\title{
EVALUASI TINGKAT PELAYANAN JALAN PERKERASAN KAKU DENGAN METODE PCI (PAVEMENT CONDITION INDEX) - STUDI KASUS JL. AHMAD RAZAK, JL. TANDIPAU \& JL. KHM. KASIM KOTA PALOPO
}

\author{
ABDIAS TANDY ARRANG \\ Pegawai Dinas Pekerjaan Umum Kota Palopo
}

\begin{abstract}
ABSTRAK
Beban lalu lintas yang berulang-ulang seiring dengan berjalannya waktu akan menimbulkan kerusakan yang berdampak pada menurunnya tingkat pelayanan jalan. Hal ini terjadi bukan hanya pada struktur perkerasan lentur tapi juga pada perkerasan kaku. Salah satu cara yang dapat digunakan untuk menilai tingkat pelayanan jalan adalah metode PCI (Pavement Condition Index).

Penelitian ini dilakukan dengan melakukan survey dengan mengamati secara visual jenis-jenis kerusakan dan tingkat kerusakan yang ada di sepanjang Jl. Ahmad Razak, Tandipau dan KHM Kasim di Kota Palopo. Data survey pengamatan kemudian diolah yang akan menghasilkan nilai numerik PCI yang dapat mengindikasikan tingkat pelayanan pada jalan yang diteliti.

Hasil penelitian menunjukkan bahwa Jl. Ahmad Razak memiliki nilai PCI 87 dengan ratingGood, sementara Jl. Tandipau nilai PCI 85 dengan rating satisfactory dan Jl. KHM Kasim nilai PCI 91 dengan rating Good.
\end{abstract}

\section{Kata Kunci : PCI (Pavement Condition Index),Rating, Perkerasan Kaku}

\section{PENDAHULUAN}

Pekerjaan konstruksi jalan dengan menggunakan struktur perkerasan kaku (rigid pavement) yang pertama kali di Kota Palopo dilaksanakan pada tahun 2011 pada tiga ruas jalan yaitu Jl. Achmad Razak, Jl. Tandipau dan Jl. KHM Kasim. Tiga ruas jalan merupakan jalan yang berada pada sisi barat kota dan merupakan jalan yang diperuntukkan bagi kendaraan berat dan bus antar kota yang melewati Kota Palopo dari arah selatan menuju utara demikian pula sebaliknya. Jenis perkerasan kaku dipilih untuk ketiga ruas ini dengan harapan dapat menahan beban lalu lintas dengan tonase yang tinggi yang melewati ruas-ruas jalan tersebut. 
Seiring dengan berjalannya waktu dan beban yang berulang - ulang, kondisi jalan akan mulai mengalami penurunan. Suatu penelitian terhadap kondisi jalan dibutuhkan untuk mengetahui bagaimana kondisi jalan tersebut. Salah satu cara yang dapat digunakan untuk menilai tingkat pelayanan jalan adalah metode $P C I$ (Pavement Condition Index). Cara ini sangat sederhana karena tidak membutuhkan alat khusus. Survey dilaksanakan dengan pengamatan visual, dan hasil dari metode $P C I$ dapat dijadikan acuan bagi jenis penanganan yang akan dilaksanakan untuk mempertahankan bahkan meningkatkan kembali pelayanan jalan yang ada.

\section{TUJUAN PENELITIAN}

1. Mengidentifikasi jenis kerusakan jalan.

2. Menentukan nilaiPavement Condition Index (PCI) dan tingkat kondisi perkerasan (Pavement Caondition Rating)

3. Memberikan rekomendasi untuk perbaikan kerusakan jalan berdasarkan tingkat dan jenis kerusakan yang terjadi.

\section{LANDASAN TEORI}

\section{A. Pavement Condition Index (PCI)}

Metode penelitian ini mengunakan metode PCI (Pavement Conditiont Index)dimana yang mana menggunakan pengamatan secara visual pada lokasi/objek. Metode PCIpertama kali diperkenalkan oleh Departemen Pertahanan USA, U.S Army Corps Of Engineers. Metode ini biasa digunakan dalam menilai tingkat kerusakan ruas jalan. $P C I$ memberikan tingkat kondisi perkeraasan berdasarkan kerusakan yang diamati pada permukaan jalan beton, namun $P C I$ tidak dapat digunakan untuk mengukur kapasitas struktural juga tidak dapat digunakan untuk mengukur secara langsung kerataan atau kekasaran permukaan perkerasan.PCI adalah indeks numerik, mulai dari 0 untuk perkerasan gagal dan 100 untuk perkerasan dalam kondisi sempurna. 


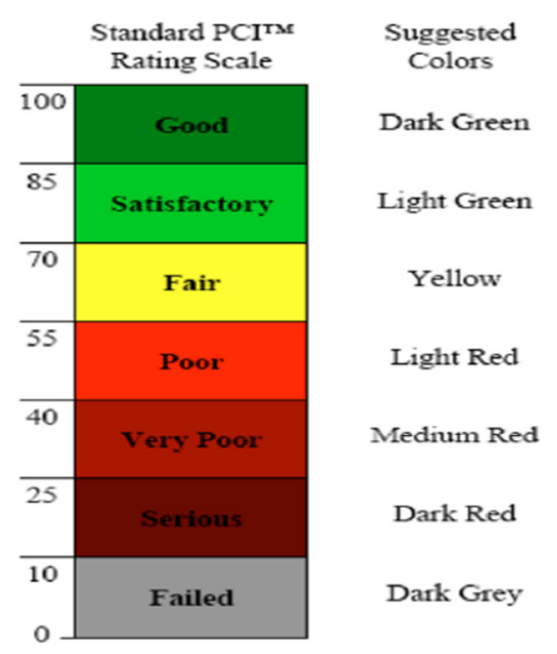

\section{Gambar 1. Rating atau Peringkat Hasil Akhir Pavement Condition Index (PCI) Kerusakan Perkerasan Jalan}

B. Jenis-Jenis Kerusakan Pada Perkerasan Kaku

Menurut Shahin (2006) jenis-jenis kerusakan pada perkerasan kaku adalah sebagai berikut : blow up, corner break, longitudinal crack, durability crack, joint seal damage, patching smalling, patching utility cut, popouts, pumping, scaling/map crack, faulting, shattered slab, shrinkage crack, spalling joint dan spalling corner.

\section{Tingkat Kerusakan (Severity Level)}

Severity level adalah penilaian terhadap tingkat kerusakan pada tiap-tiap jenis kerusakan. Pada metode PCI (Shahin 1994), severity level terdiri dari : Low $(L)$ di mana tingkat kerusakan yang terjadi sangat kecil, Medium(M)di mana tingkat kerusakan yang terjadi sedang dan $H i g h(H)$ di mana tingkat kerusakan yang terjadi telah berada pada tingkat yang sangat parah.

D. Cara Penentuan Nilai Tingkat Pelayanan

1. Density (Kadar Kerusakan)

Density atau kadar kerusakan adalah persentase luasan dari suatu jenis kerusakan terhadap luasan suatu unit segmen yang diukur dengan meter persegi atau meter panjang. Nilai Density suatu jenis kerusakan dibedakan berdasarkan tingkat kerusakannya.Rumus Density adalah sebagai berikut : 
Density $=\frac{A d}{A s} \times 100 \%$

Di mana :

Ad = Luas Total/Panjang Total Jenis Kerusakan untuk tiap Tingkat Kerusakan $\left(\mathrm{m}^{2}\right.$ atau $\left.\mathrm{m}\right)$

As $=$ Luas Total Unit Segmen $\left(\mathrm{m}^{2}\right)$

2. Deduct Value (Nilai Pengurangan)

Deduct Value adalah nilai pengurangan unutk tiap jenis kerusakan yang diperoleh dari kurva hubungan antara Density dengan Deduct Value. Deduct Value juga dibedakan atas tingkat kerusakan untuk tiap-tiap jenis kerusakan.

\section{Total Deduct Value (TDV)}

$T D V$ adalah nilai total dari individual deduct value untuk tiap jenis kerusakan dan jenis kerusakan yang ada pada suatu unit penelitian.

4. Corrected Deduct Value (CDV)

$C D V$ diperoleh dari kurva hubungan antara nilai $T D V$ dengan nilai $C D V$ dengan pemilihan lengkung kurva sesuai dengan jumlah nilai individual deduct value yang mempunyai nilai lebih besar dari 2 .

Jika nilai $C D V$ telah diketahui, Maka nilai $P C I$ untuk tiap unit dapat diketahui dengan rumus:

$P C I(\mathrm{~s})=100-C D V$

Di mana :

$P C I(\mathrm{~s}) \quad=P C I$ untuk tiap unit

$C D V=$ Corrected Deduct Value untuk tiap unit

Untuk nilai PCI secara keseluruhan adalah :

$\mathrm{PCI}=\frac{\sum P C I(s)}{N}$.

Di mana :

PCI = Nilai Pavement Conditiont Index

PCI (s) = Nilai PCI Untuk tiap Unit 


$$
\mathrm{N} \quad=\text { Jumlah Unit }
$$

\section{Klasifikasi Nilai PCI}

Berdasarkan nilai PCI yang diperoleh pada point 4 di atas, maka dapat ditentukan nilai tingkat pelayanan dari sebuah ruas jalan.Adapun tingkat pelayanan masing-masing nilai PCI dapat di lihat pada Gambar 1.

\section{METODE PENELITIAN}

Perkerasan jalan beton ruas Jl. Ahmad Razak, Jl. TandipaudanJl.KHM. Kasim merupakan jalan yang bersambung dengan lalu lintas 2 lajur 2arah.Lebar rata-rata jalan 8 meter dengan total panjang $3.980 \mathrm{~m}$.Survey diawali dari persimpangan $\mathrm{Jl}$. Andi Djemma dengan Jl. Ahmad Razak, kemudian Jl. Tandipau dan berakhir pada persimpangan J1. KHM Kasim dengan J1. Dr. Ratulangi. Ketiga jalan tersebut dibagi dalam 172 unit segmen perkerasan, dengan ukuran rata-rata $4 \mathrm{~m} \mathrm{x}$ $5 \mathrm{~m}$.

Data hasil survey kemudian diolah dengan menurut langkah-langkah seperti pada point (D) di atas.

\section{HASIL PENELITIAN DAN PEMBAHASAN}

1. Gambaran Kerusakan Jalan

Jenis dan jumlah kerusakan pada lokasi penelitian dapat dilihat pada Gambar

2.

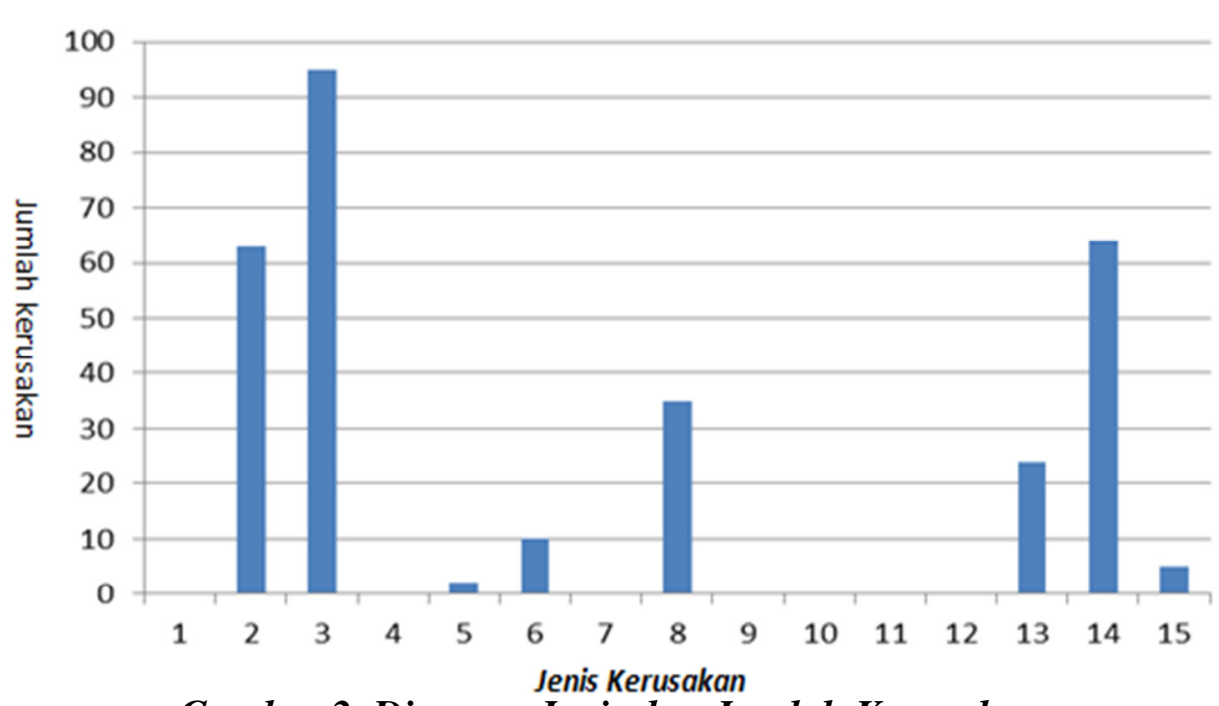

Gambar 2. Diagram Jenis dan Jumlah Kerusakan
Ket. Jenis Kerusakan : 1. Blow Up 2. Corner Break 3. Longitudinal 4. D' Crack 5. Joint Seal Damage 6. Patching 7. Patching Cut 8. Popouts 9. Pumping 10.Scalling/Map Crack 11. Faulting 12. Shattered Slab 13. Shrinkage Crack 14. Spalling Joint 15. Spalling Corner 
Berdasarkan diagram diatas, jenis kerusakan yang paling banyak disepanjang ruas jalan yang menjadi lokasi penelitian adalah kerusakan jenisLongitudinal Crack sebanyak 95 kerusakan.

2. Nilai PCI

a) Jl. Ahmad Razak

Hasil perhitungan nilai PCI untuk ruas Jl. Ahmad Razak dapat dilihat pada Tabel 1.

Tabel 1. Hasil Rekapitilasi Nilai PCI dari Unit Sampel Ruas Jl. A. Razak

\begin{tabular}{|c|c|c|c|c|}
\hline $\begin{array}{c}\text { Nomor } \\
\text { sample unit }\end{array}$ & TDV & $\mathbf{q}$ & CDV & PCI \\
\hline 1 & 18 & 3 & 10 & 90 \\
\hline 2 & 27 & 3 & 16 & 84 \\
\hline 3 & 20 & 3 & 12 & 88 \\
\hline 4 & 27,5 & 5 & 11 & 89 \\
\hline 5 & 12 & 4 & 5 & 95 \\
\hline 6 & 28 & 4 & 18 & 82 \\
\hline 7 & 41 & 4 & 23 & 77 \\
\hline 8 & 31 & 4 & 17 & 83 \\
\hline 9 & 20,5 & 3 & 11 & 89 \\
\hline 10 & 18 & 3 & 10 & 90 \\
\hline 11 & 20 & 3 & 12 & 88 \\
\hline 12 & 36 & 4 & 20 & 80 \\
\hline 13 & 15 & 3 & 9 & 91 \\
\hline 14 & 19,5 & 3 & 11 & 89 \\
\hline 15 & 5,5 & 1 & 6 & 94 \\
\hline 16 & 37 & 4 & 21 & 79 \\
\hline 17 & 22 & 2 & 17 & 83 \\
\hline 18 & 32 & 2 & 19 & 81 \\
\hline 19 & 17 & 3 & 9 & 91 \\
\hline 20 & 23 & 3 & 13 & 87 \\
\hline 21 & 6 & 2 & 4 & 96 \\
\hline 22 & 3 & 1 & 2 & 98 \\
\hline 23 & 23 & 3 & 13 & 87 \\
\hline 24 & 21 & 2 & 16 & 84 \\
\hline 25 & 11 & 1 & 12 & 88 \\
\hline 26 & 11,5 & 2 & 9 & 91 \\
\hline 27 & 11 & 2 & 9 & 91 \\
\hline
\end{tabular}




\begin{tabular}{|c|c|c|c|c|}
28 & 29 & 4 & 23 & 77 \\
\hline 29 & 18,5 & 3 & 11 & 89 \\
\hline 30 & 27 & 3 & 16 & 84 \\
\hline 31 & 12,5 & 3 & 7 & 93 \\
\hline 32 & 14 & 2 & 12 & 88 \\
\hline 33 & 14 & 2 & 12 & 88 \\
\hline 34 & 18 & 2 & 14 & 86 \\
\hline 35 & 24 & 3 & 14 & 86 \\
\hline 36 & 8 & 1 & 8 & 92 \\
\hline 37 & 14 & 2 & 12 & 88 \\
\hline 38 & 14 & 2 & 12 & 88 \\
\hline 39 & 21 & 3 & 11 & 89 \\
\hline 40 & 21,5 & 5 & 12 & 88 \\
\hline 41 & 34 & 4 & 21 & 79 \\
\hline 42 & 37,5 & 5 & 19 & 81 \\
\hline 43 & 18 & 3 & 10 & 90 \\
\hline 44 & 16 & 3 & 15,5 & 84,5 \\
\hline \multicolumn{5}{|l}{ Total } \\
\hline
\end{tabular}

$$
\begin{array}{r}
\mathrm{PCI}=\frac{\sum P C I(s)}{N} \\
\mathbf{P C I}=\frac{\mathbf{3 8 3 5}, \mathbf{5}}{\mathbf{4 4}} \\
\text { PCI }=\mathbf{8 7}
\end{array}
$$

Hasil akhir dari rekapitulasi nilai PCI ruas Jl. A. Razak memiliki nilai PCI 87 dengan rating 'Good'.

b) J1. Tandipau

\begin{tabular}{|c|c|c|c|c|}
\hline $\begin{array}{c}\text { Nomor } \\
\text { sample unit }\end{array}$ & TDV & q & CDV & PCI \\
\hline 1 & 31 & 3 & 22 & 78 \\
\hline 2 & 19,5 & 5 & 8 & 92 \\
\hline 3 & 44 & 4 & 24 & 76 \\
\hline 4 & 24,5 & 4 & 12 & 88 \\
\hline 5 & 32,5 & 6 & 10 & 90 \\
\hline 6 & 26 & 4 & 14 & 86 \\
\hline 7 & 16 & 1 & 13 & 87 \\
\hline 8 & 30 & 4 & 17 & 83 \\
\hline 9 & 19 & 2 & 14 & 86 \\
\hline 10 & 19,5 & 3 & 10 & 90 \\
\hline
\end{tabular}




\begin{tabular}{|c|c|c|c|c|}
\hline 11 & 12 & 2 & 9 & 91 \\
\hline 12 & 16 & 3 & 8 & 92 \\
\hline 13 & 20 & 3 & 11 & 89 \\
\hline 14 & 35 & 4 & 15 & 85 \\
\hline 15 & 45,5 & 7 & 25 & 75 \\
\hline 16 & 35 & 2 & 37 & 63 \\
\hline 17 & 26 & 2 & 22 & 78 \\
\hline 18 & 10 & 2 & 6 & 94 \\
\hline 19 & 37 & 5 & 20 & 80 \\
\hline 20 & 14 & 1 & 14 & 86 \\
\hline 21 & 19 & 3 & 10 & 90 \\
\hline 22 & 16 & 1 & 11 & 89 \\
\hline 23 & 15,5 & 2 & 11 & 89 \\
\hline \multicolumn{5}{|l|}{ Total } \\
\hline
\end{tabular}

$$
\begin{gathered}
\mathrm{PCI}=\frac{\sum P C I(s)}{N} \\
\mathrm{PCI}=\frac{1957}{23} \\
\mathrm{PCI}=85
\end{gathered}
$$

Hasil akhir dari rekapitulasi nilai PCI ruas Jl. Tandipau memiliki nilai PCI 85 dengan rating 'Satisfactory'.

c) Jl. KHM Kasim

Hasil perhitungan nilai PCI untuk ruas Jl. KHM Kasim dapat dilihat pada Tabel 3.

Tabel 2. Hasil Rekapitilasi Nilai PCI dari Unit Sampel Ruas Jl. KHM Kasim

\begin{tabular}{|c|c|c|c|c|}
\hline $\begin{array}{c}\text { Nomor } \\
\text { sample unit }\end{array}$ & TDV & q & CDV & PCI \\
\hline 1 & 12 & 1 & 10 & 90 \\
\hline 2 & 16 & 3 & 8 & 92 \\
\hline 3 & 17 & 2 & 11 & 89 \\
\hline 4 & 9 & 2 & 6 & 94 \\
\hline 5 & 15,5 & 3 & 9 & 91 \\
\hline 6 & 5,5 & 1 & 4 & 96 \\
\hline 7 & 30 & 4 & 21 & 79 \\
\hline 8 & 15 & 2 & 10 & 90 \\
\hline
\end{tabular}




\begin{tabular}{|c|c|c|c|c|}
9 & 26,5 & 4 & 12 & 88 \\
\hline 10 & 20 & 3 & 13 & 87 \\
\hline 11 & 10 & 1 & 8 & 92 \\
\hline 12 & 4 & 1 & 2 & 98 \\
\hline \multicolumn{6}{|c|}{ Total } \\
\hline
\end{tabular}

$$
\begin{gathered}
\mathrm{PCI}=\frac{\sum P C I(s)}{N} \\
\mathrm{PCI}=\frac{1086}{12} \\
\text { PCI }=91
\end{gathered}
$$

Hasil akhir dari rekapitulasi nilai PCI ruas Jl. M.Kasim memiliki nilai PCI 91 dengan rating 'Good'.

3. Penanganan Kerusakan

Untuk menjaga agar kerusakan yang terjadi tidak semakin meluas dan tingkat kerusakan tidak semakin parah serta mengembalikan tingkat pelayanan jalan yang mulai turun, maka berikut diberikan saran perbaikan untuk masingmasing kerusakan yang terjadi.

a) Corner Break

Saran penanganan : - retakan tanpa pecahan, penanganannya dengan pengisian celah retakan, retakan yang disertai dengan pecahan penanganannya dengan rekonstruksi parsial.

b) Longitudinal / Linear Crack

Saran penanganan : untuk retak dengan celah $<5 \mathrm{~mm}$, penanganannya dengan pengisian celah retak dengan aspal, untuk retak $\geq 5$ penanganannya dengan rekonstruksi setempat.

c) Joint Seal Damage

Saran penanganan : penggantian bahan pengisi sambungan / seal

d) Patching, $<5 \mathrm{FT}^{2}$

Saran penanganan : dengan penambalan ulang

e) Popouts 
Saran penanganan : Pelapisan ulang tipis

f) Shrinkage Crack

Saran penanganan : untuk retak dengan celah $<5 \mathrm{~mm}$, penanganannya dengan pengisian celah retak dengan aspal, untuk retak $\geq 5$ penanganannya dengan rekonstruksi setempat.

g) Spalling Joint

Saran penanganan : untuk retak dengan celah $<5 \mathrm{~mm}$, penanganannya dengan pengisian celah retak dengan aspal, untuk retak $\geq 5$ penanganannya dengan rekonstruksi setempat.

h) Spalling Corner

Saran penanganan : untuk retak dengan celah $<5 \mathrm{~mm}$, penanganannya dengan pengisian celah retak dengan aspal, untuk retak $\geq 5$ penanganannya dengan rekonstruksi setempat.

\section{KESIMPULAN}

1. Jenis kerusakan yang terjadi yaitu Longitudinal 95 kerusakan, Corner Break 63 kerusakan, Joint Seal Damage 2 Kerusakan,Patching 10 kerusakan, Popouts 35 kerusakan, Shrinkage Crack 24 kerusakan, Spalling Joint 63 kerusakan, Spalling Corner 5 kerusakan.

2. Nilai Pavement Condition Index (PCI) yang menggambarkan tingkat pelayanan masing-masing ruas jalan adalah :

- Ruas Jalan A.Razak memiliki nilai PCI sebesar 87 dengan rating 'Good' .

- Ruas Jalan Tandipau memiliki nilai PCI sebesar 85 dengan rating 'Satisfactory'

- Ruas Jalan M.Kasim memiliki nilai PCI sebesar 91 dengan rating 'Good'

3. Rekomendasi dan saran perbaikan perkerasan jalan untuk kerusakan :

- Corner Break, Longitudinal, Joint Seal Damage, Shrinkage Crack, Spalling Joint, Spalling Corner adalah untuk retak dengan celah $<5$ 
$\mathrm{mm}$, penanganannya dengan pengisian celah retak dengan aspal, untuk retak $\geq 5 \mathrm{~mm}$ penanganannya dengan rekonstruksi setempat.

- $\quad$ Patching Saran penanganan adalah dengan penambalan ulang

- $\quad$ Popouts Saran penanganan adalah Pelapisan ulang tipis.

\section{SARAN}

1. Untuk menjaga fungsi pelayanan jalan yang baik padaJl. A. Razak, Jl. Tandipau dan Jl.KHM. Kasim, diperlukan pemeliharaanjalansecara rutin dan berkala.

2. Perlu dilakukan studi lebih lanjut untuk terkait daya dukung tanah pada subgrade, yang mana hal ini merupakan kemungkinan penyebab terjadinya jenis kerusakan Longitudinal Crack sebagai jenis kerusakan yang paling banyak terjadi pada lokasi penelitian.

\section{DAFTAR PUSTAKA}

1. ASTM, Designation : D6433 - 07, "Standard Practice For Roads \& Parking Lots Pavement Condition Index Survey”, ASTM, USA.

2. Sahin, 1994, "Pavement Conditiont Index (PCI)", USA.

3. Shahin,M.Y., 2006, "Pavement Managemen for airport,Roads and parking Lots,Second Edition”, Springer, USA.

4. US Departement of Transportation Aviaton Administration,"Guidelines and procedures for maintenance", USA. 